\title{
Exploring the Relationship between Stay-abroad Experiences, Frequency Effects, and Context Use in L2 Idiom Comprehension
}

\author{
Ferran Suñer \\ Catholic University of Louvain (UCL), Belgium
}

\begin{abstract}
This article explores to what extent a stay-abroad experience of L2 learners leads to more productive use of contextual clues and better benefits from frequency effects in $\mathbf{L} 2$ idiom comprehension. To this end, seventy-two learners of German (L1 French) were presented with a test on idiom comprehension that contained items both with and without a context and differing degrees of frequency. Furthermore, the participants completed a questionnaire on their stay-abroad experience (length of stay, country, etc.) as well as providing other data from their linguistic biography (language proficiency level, other languages, etc.). The results show that participants with a stay-abroad experience neither outperformed those without such an experience nor benefited from frequency effects and the presence of context. However, frequency was found to positively affect performance for items presented in context.
\end{abstract}

Index Terms - idioms, stay abroad, L2 learners, context, frequency effects

\section{INTRODUCTION}

The impact of a stay-abroad experience for language learning has been amply described in the literature, in some cases shaping the perception that spending time abroad will automatically contribute to qualitatively greater improvement (Kinginger, 2009; Lafford, 2006). In other cases, however, the very limited impact of stay-abroad experiences has contributed to debunking some of the myths surrounding their effectiveness, suggesting that many other factors, such as proficiency level, length of stay and out-of-class exposure to the target language, are at play (Lafford, 2006). To date, research has mainly focused on aspects of linguistic competence such as oral fluency and pronunciation (Lord, 2010; Mora \& Valls-Ferrer, 2012; Trenchs-Parera, 2009; Wood, 2007), and vocabulary acquisition (Collentine, 2004; Freed, 1998; Lafford, 2004), but has neglected other aspects such as conceptual fluency (Danesi, 2008). In fact, conceptual fluency, which allows learners to deal with figurative language in a culturally appropriate way (Littlemore et al., 2014), has been found to be highly beneficial for many areas of language learning, such as idiom comprehension, and vocabulary and grammar acquisition (Azuma, 2009; Cameron \& Low, 1999; Littlemore \& Low, 2006). Consequently, this article aims to shed some light on the impact of stay-abroad experiences on the acquisition of conceptual fluency among L2 learners. Within the category of figurative language, we will focus on metaphorical idiomatic expressions, which will be referred to as those expressions "whose meaning cannot always be readily derived from the usual meaning of its constituent elements" (Cooper, 1999, p. 233). We also argue that idioms are at least partially analyzable, conceptually motivated and reflect metaphoric thinking, which is in line with the cognitive linguistic view of idioms (Gibbs, 2007). Although idiomatic expressions are often described as very infrequent vocabulary items, they are omnipresent in a wide range of registers (Liu, 2008) and should therefore be an essential part of vocabulary teaching in the foreign language classroom (Karlsson, 2013).

Previous research has consistently shown that L2 idiom comprehension is fairly well modulated by variables such as the presence or absence of a context and the frequency effects (De Cock \& Suñer, 2018; Suñer, 2018; Türker, 2016). This is especially relevant for L2 learners with a stay-abroad experience, who are supposed to benefit even more from these factors due to their massive exposure to authentic L2 input (Freed, 1998; Lafford, 2004; Lafford, 2006; Montero, Serrano, \& Llanes, 2017; Wray, 2002, p. 186). Although highly relevant, the relationship between these variables has not yet been investigated. This study therefore aims to fill this gap by looking at whether the presence or absence of a context and the frequency of target idiomatic expressions modulate the effect of L2 learners' stay-abroad experiences on L2 idiom comprehension.

We will first briefly discuss the benefits of stay-abroad experiences for language learning and present studies that looked into the effects of the presence or absence of contextual information and the L2 frequency on L2 idiom comprehension. We will then present our study, which investigates the effect of contextual information and L2 frequency by French-speaking learners of German with and without stay-abroad experiences when processing L2 idioms. Finally, we will discuss the results of this study in the light of previous literature and draw consequences for further research and formulate pedagogical implications.

\section{LITERATURE REVIEW}




\section{A. The Impact of Stay-abroad Experiences on Linguistic Competence}

Over the past few decades, research on the impact of stays abroad has addressed aspects of the learners' linguistic competence (grammar, vocabulary, writing, oral fluency, etc.), individual learners' differences, cultural sensitivity, and external factors (length of stay, living conditions, etc.) (cf. Pinar, 2016). In this section, we will mainly focus on research in the first category (linguistic competence) that looks at aspects directly related to the variables under investigation in this study, such as vocabulary acquisition and communicative strategies.

Previous research has found L2 vocabulary size to be one of the most powerful predictors of L2 idiom proficiency (cf. Chuang, 2013), together with frequency of exposure to L2 figurative language and intra-lingual transfer (lexical ability) (see Boers, 2003; Charteris-Black, 2002). However, as far as the impact of stay-abroad experiences on vocabulary acquisition is concerned, only moderate benefits have been reported (Pinar, 2016). On the one hand, some studies found that L2 learners who had spent time abroad had an overall advantage over their counterparts who had not, in terms of a greater lexical ability (De Keyser, 1991) and a greater variety of vocabulary (Segalowitz et al., 2004; Sunderman \& Kroll, 2009). On the other hand, Collentine (2004) did not find any significant difference in the acquisition of more semantically dense words between students in the at-home learning context and those in the stay-abroad learning context. In this vein, Ife et al. (2000) suggest that the improvement in vocabulary abilities might depend on the length of stay abroad, since they found that, in a vocabulary test, learners with more time abroad outperformed those with less, even if both groups improved compared with their performance in their respective pretests. Taguchi (2011) also reports on the limited impact of stay-abroad experiences on vocabulary acquisition in that the L2 learners in the study improved their lexical access speed but not their accuracy. Dewey (2008) looked into the differences between the immersion learning context, the stay-abroad context and the learning context at home in terms of lexical learning. The results show that students in immersion programs significantly improved their lexical learning in comparison with those in the athome and stay-abroad learning contexts (cf. also Freed, Segalowitz \& Dewey, 2004). The author points to the importance of the time spent using the target language out of class as the most critical factor affecting vocabulary acquisition across the different learning contexts. Other studies found that the benefits of stay-abroad experiences for L2 learners were more noticeable with children than with adults, indicating that age is another factor at play (Llanes \& Muñoz, 2013). Specially relevant is the study by Wood (2007), which investigated the use of formulaic sequences in relation to spontaneous speech of learners in the stay-abroad context. The author analyzed the students' narrative retells over a period of six months and found that the students did significantly improve their level of fluency, the use of formulaic sequences being one of the most important indicators. Accordingly, stay-abroad experiences seem to be associated with increased use of formulaic language, which also includes the use of idioms (Gibbs, 2007).

The importance of communicative strategies for dealing with comprehension difficulties in L2 idiom comprehension has been stressed in many studies (Cooper, 1999), the use of contextual information being the most effective strategy to infer the meaning in L2 idiom comprehension (De Cock \& Suñer, 2018; Littlemore, 2008; Liu, 2008; Türker, 2016). In this vein, Saleh and Zakaria (2013) investigated the strategies used by L2 learners when they encountered lowfrequency and unknown idioms and found that lexical inferencing in the context was the most successful strategy, followed by looking for potential L1 equivalents (see also Rohani, Ketabi, \& Tavakoli, 2012; Taki \& Namy, 2013). Consequently, we assume that a large amount of exposure to authentic and rich L2 input during a stay abroad might provide L2 learners with a greater ability to successfully use communicative strategies such as the use of contextual information (Freed, 1998; Lafford, 2004; Lafford, 2006; Montero et al., 2017). Overall, the reported findings regarding the gains in vocabulary size and the communicative strategies during a stay abroad suggest that L2 learners with stayabroad experience might use the contextual information more effectively than their counterparts without this experience.

\section{B. Context and Frequency as Variables Affecting L2 Idiom Comprehension}

In this section, we will present the few studies on L2 idiom comprehension that include the presence or absence of contextual information and frequency effects as variables, with special emphasis on stay-abroad experiences.

The effect of context in L2 idiom comprehension has been widely investigated (Cooper, 1999; De Cock \& Suñer, 2018; Ferreira, 2008; Irujo, 1986; Liontas, 2002; Suñer, 2018). However, to the best of our knowledge, only two studies have taken the stay-abroad experience of learners under investigation as a variable affecting L2 idiom comprehension. In both cases, the focus was not on the stay-abroad experience, so neither the study design nor the sample size allows strong claims. De Cock and Suñer (2018) looked into how L2 learners of Spanish processed metaphorical expressions concerning taboo topics with different degrees of conceptual distance to their respective L1 equivalents. The authors found that stay-abroad experience was a good predictor for L2 metaphor comprehension and explain this finding by the fact that taboo topics are much more frequent in informal registers, which tend to be avoided in the formal language learning context. Furthermore, Suñer (2018) investigated whether the presence or absence of a context and the conceptual and formal distance to the L1 equivalents affect L2 idiom comprehension. In addition, he checked for other variables such as stay-abroad experience and proficiency level of the participants. The results show that L2 idiom comprehension is positively correlated with the general proficiency level of learners, rather than with stay-abroad experience. Although very promising, these findings are limited in that they do not allow further explanation about how factors such as length of stay and language proficiency level modulate the impact of stay-abroad experiences on L2 idiom comprehension. 
With regard to the frequency effects, it can be argued, in very broad terms, that high-frequency idioms are associated with easier comprehension due to their salience (Giora, 2003). For example, Arnon and Snider (2010) found that comprehension of four-word compositional phrases by L1 speakers was positively correlated with high frequency. Such effects are very unlikely to be found among L2 learners, since the relatively limited L2 input prevents them encountering the target expressions often enough to achieve native-like idiomaticity (Ellis, 2012; Granger, 2001). However, this might not be the case for L2 learners with stay-abroad experiences, who might develop a greater sensitivity to idiomaticity than their counterparts, as well as storing and processing such collocations in a more nativelike way (Kim \& Kim, 2012). Finally, it is worth noting that, to date, only the study by Türker (2016) has examined the extent to which L1 frequency affects L2 idiom comprehension, showing that highly frequent L1 equivalents are associated with better L2 idiom comprehension. This study, however, does not include stay-abroad experiences as a variable, so no consequences can be drawn from the results in this regard. Accordingly, our own study will focus on L2 frequency instead of L1 frequency, since L2 frequency is more likely to affect L2 idiom comprehension in the case of learners with a stay-abroad experience. Thus, we expect that L2 learners with stay-abroad experiences will benefit from high-frequency idiomatic expressions more than those without stay-abroad experiences.

\section{The PRESENT STUdy}

Against this backdrop, this study aims to substantially contribute to a deeper understanding of the factors modulating the effect of stay-abroad experiences on L2 idiom comprehension by addressing the following research questions:

- To what extent do learners with a stay-abroad experience make more efficient use of contextual information in L2 idiom comprehension than their counterparts without a stay-abroad experience?

- To what extent do learners with a stay-abroad experience benefit from frequency effects in L2 idiom comprehension?

- What is the relationship between proficiency level, length of stay and frequency with regard to the use of contextual information in L2 idiom comprehension?

\section{A. Participants}

The study was conducted with seventy-two learners of German as a foreign language with French as L1 (female n= 55; male $n=17$ ). The participants were enrolled in the Master's degree programs in multilingual communication or translation \& interpreting at the Catholic University of Louvain (UCL) and the University of Mons (Belgium). Based on the tests carried out within the programs and the self-assessment of the participants, their language proficiency level averaged B2-C1 according to the Common European Framework of Reference for Languages (CEFR). However, as we asked for the proficiency level for each aspect of competence to be specified, there might be some cases with a level above $\mathrm{C} 1$ or below B2. Thirty-four students $(47.2 \%)$ had a language proficiency level of $\mathrm{C} 1$ or higher, while thirty-eight $(52.8 \%)$ were B2 or lower. Forty-three students indicated that they had spent at least three months abroad, while twentynine did not have any stay-abroad experience in a German-speaking country. In order to consider the effect of length of stay on L2 idiom comprehension, we differentiated between two sub-groups within those with a stay abroad: Students with a short stay $(\geq 3$ and $<6, n=22)$ and students with a longer stay $(\geq 6$ months, $n=21)$. The main purpose of their stay abroad was a student exchange within the Erasmus mobility program $(93.02 \%, \mathrm{n}=40)$; other reasons indicated were internships, language courses or another type of exchange (e.g. school exchange).

\section{B. Instruments}

In order to test the research questions, an idiom comprehension test was created covering the presence or absence of contextual information and the frequency as variables under investigation. Twelve idiomatic expressions were chosen according to the different dimensions represented in Table I and assigned to the respective cells. Accordingly, each cell was covered by at least two or more different items.

TABLE I

VARIABLES OF THE METAPHOR COMPREHENSION TEST

\begin{tabular}{|l|l|}
\hline Context & Frequency \\
\hline \multirow{2}{*}{ Items without context } & Low frequency \\
\cline { 2 - 2 } & High frequency \\
\hline \multirow{2}{*}{ Items with context } & Low frequency \\
\cline { 2 - 2 } & High frequency \\
\hline
\end{tabular}

For those items requiring the presence of a context, we extracted examples from the DWDS corpus (Digitales Wörterbuch der Deutschen Sprache) as well as from journalistic texts, the purpose being to present participants with real usage events rather than explanatory contexts from which the meaning can be easily inferred. This aligns well with the claims made in previous research, to the effect that pedagogically manipulated contexts do not represent authentic usage of idioms (Boers, 2003). The following extract shows an example of an item that was presented with a context:

(1) "Der Mensch jagt ständig nach Höchstleistungen. Das Guinness-Buch schreibt sie seit 60 Jahren auf. Die Grenze zwischen Weltrekord und Wahnsinn ist oft fließend. Was treibt Menschen an, teilweise Kopf und Kragen zu riskieren?.” (Klemm, 2014, para. 1) [Engl. Humans constantly strive for top performance. The Guinness Book of 
Records has been documenting their achievements for 60 years. The dividing line between a world record and insanity is often blurred. What makes people risk their neck?]

As far as the frequency of the items is concerned, we categorized the items either as high frequency or low frequency. The threshold for the frequency was set on the basis of the frequency values in the corpus German Web 2013 (deTenTen13). Assuming that metaphorical idiomatic expressions are relatively infrequent vocabulary items compared with single vocabulary units (Liu, 2008), we set the threshold at 0.30 tokens per million words, which is the frequency value of very common metaphorical idiomatic expressions in the corpus used for this study. By doing so, we assigned six of the chosen items to the less frequently occurring, and six to the more frequently occurring. The normalized frequency value for frequently occurring items was 1.05 tokens per million words, compared with 0.10 tokens per million words for the less frequently occurring.

Furthermore, participants were asked to complete a questionnaire concerning their linguistic biography (e.g. proficiency level in German, knowledge of other foreign languages, etc.), which included several questions about their stays abroad (length, purpose, country, etc.).

\section{Data Analysis}

For each item in the idiom comprehension test, participants were asked to indicate the meaning and/or suggest an equivalent idiomatic expression in their L1. For example, for the target expression auf den Kopf stellen (Engl. "to turn something upside down"), we accepted both the equivalent idiomatic expression (Fr. mettre qc. sens dessus dessous) and the concrete meaning (Fr. bouleverser = "to mess up"). Correct answers were credited with 1 point, irrespective of whether participants indicated both the meaning and the L1 equivalent or only one of the two. In order to examine the accuracy of the answers, two independent raters were brought in, both French native speakers with a high-proficient level of German. They had been trained beforehand with a subset of the data in order to ensure consistency in their assessments. They agreed on $95.2 \%$ of the answers, which according to Cohen's Kappa refers to a substantial agreement $(k=0.741, p<0.000)$. Disagreements were discussed until consensus on final coding of the answers was reached. After analysis of the final coding, two items were discarded because of low reliability and/or poor item distribution characteristics.

\section{Procedure}

After having signed a letter of consent, which stated the main purpose of the study and informed the participants about the procedure for data collection and the data protection policy, the participants completed the questionnaire and were then presented with the idiom comprehension test. The test was carried out in class, in order to ensure that no external resources were used during the study. The paper forms were collected after the study. Conducting the study took approximately 25 minutes.

\section{RESULTS}

\section{A. Quantitative Analysis of Learners' Answers}

Table II shows the descriptive statistics of the idiom comprehension test (by-item analysis). In order to analyze the extent to which the variables under investigation (context, L2 frequency and stay-abroad experience) predict performance in the idiom comprehension test, a binary logistic regression with random effects (generalized linear mixed model) was conducted. In addition to the fixed effects (frequency and context), we included the items and the subjects as random effects in the model, since they contributed to many data points in our sample. In the following, we will first analyze the main effects of the variables and then report on the two-way interaction effects.

TABLE II

RESULTS ON METAPHOR COMPREHENSION TEST (BY ITEM)

RESULTS ON METAPHOR COMPREHENSION TEST (BY ITEM)
\begin{tabular}{|l|l|l|l|}
\hline Variables & Mean & SD & N \\
\hline Participants with stay-abroad experience & 0.248 & 0.289 & 72 \\
Participants without stay-abroad experience & 0.235 & 0.284 & 72 \\
\hline High language proficiency & 0.201 & 0.288 & 72 \\
Low language proficiency & 0.251 & 0.319 & 72 \\
\hline Items with context & 0.230 & 0.308 & 72 \\
Items without context & 0.254 & 0.306 & 72 \\
\hline Items with high frequency & 0.598 & 0.399 & 72 \\
Items with low frequency & 0.064 & 0.101 & 72 \\
\hline
\end{tabular}

Regarding the effect of stay-abroad experiences of L2 learners, both groups of participants achieved similar results. As expected, no significant fixed effect of this variable on L2 idiom comprehension was found $(F(1,696)=2.272, p=$ 0.132). We also looked at whether the language level affected L2 idiom comprehension. Surprisingly, the mean scores show that participants with lower language proficiency achieved slightly better results than their counterparts with higher language proficiency. However, the difference between both categories was found to be not significant $(F(1,696)$ $=3.739, p=0.054)$. 
As for the presence or absence of a context, the mean scores reveal no marked differences in the proportion of correct answers across the categories (with and without context). The fixed effect was not significant $(F(1,696)=0.032, p=$ 0.858). In contrast, the participants performed considerably better when the items were high frequency. The results of the binary logistic regression revealed that high-frequency items were associated with a significantly higher likelihood that the participants answered correctly $(F(1,696)=6.206, p=0.013)$.

With regard to the influence of a stay-abroad experience on the use of contextual information to infer the meaning of idioms (research question 1), analysis of the mean scores reveals that there are no noticeable differences between the different categories. Items presented with context were found to be slightly easier to comprehend by participants without stay-abroad experience than by their counterparts with stay-abroad experience (stay abroad $M=0.221, S D=$ 0.298 ; no stay abroad $M=0.238, S D=0.326$ ). The opposite tendency was true for the items presented without context, since participants with stay-abroad experience outperformed those without stay-abroad experience (stay abroad $M=$ $0.277, S D=0.323$; no stay abroad $M=0.232, S D=0.292$ ). The binary logistic regression reveals that the two-way interaction effect context $*$ stay abroad was not significant $(F(1,696)=0.035, p=0.851)$, which means that a stay abroad is not associated with a higher proportion of correct answers for items with context.

Regarding the effect of language level on participants with and without a stay-abroad experience, we found in both cases that those with lower language proficiency outperformed those with higher language proficiency by around 0.1 points (stay abroad * high level $M=0.205, S D=0.106 ;$ stay abroad $*$ low level $M=0.302, S D=0.135 ;$ no stay abroad * high level $M=0.135, S D=0.083$; no stay abroad * low level $M=0.239, S D=0.126)$. However, the fixed effect of the two-way interaction stay abroad * language level indicates that the proportion of correct answers does not vary significantly across these categories $(F(1,696)=0.160, p=0.689)$.

As far as the relationship between stay-abroad experiences and frequency effects is concerned (research question 2), analysis of the mean scores reveals that there are no substantial differences across the categories: Participants with and without stay-abroad experiences both achieved substantially better results for the high-frequency items than for the lowfrequency items (stay abroad * high-frequency $M=0.593, S D=0.205$; stay abroad * low-frequency $M=0.072, S D=$ 0.061 ; no stay abroad * high-frequency $M=0.524, S D=0.220$; no stay abroad $*$ low-frequency $M=0.040, S D=0.037$ ) (see Figure 1). The between-group comparison of the mean scores also shows that participants with stay-abroad experience slightly outperformed those without stay-abroad experience. As expected, the interaction effect stay abroad * frequency was found to be not significant $(F(1,696)=0.473, p=0.492)$.

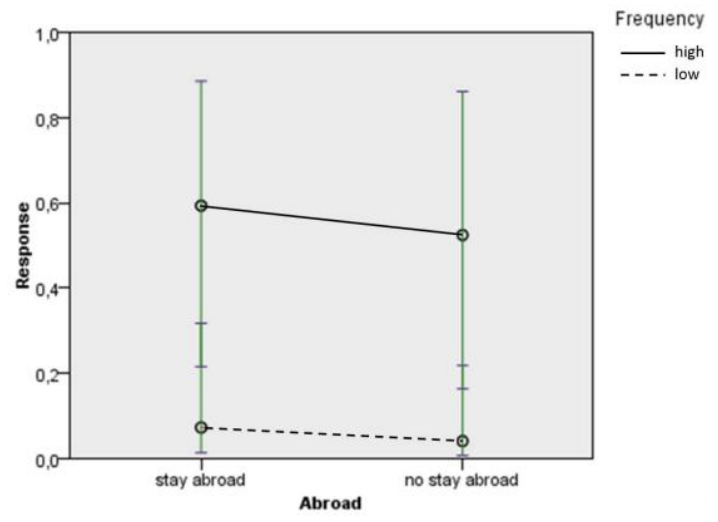

Figure 1. Results of the idiom comprehension test by L2 frequency and stay-abroad experience (by-item analysis).

Our next step was to look at whether the use of contextual information can be predicted by factors such as language proficiency, length of stay and frequency (research question 3). Regarding the influence of the language level on the use of the context when dealing with L2 idioms, analysis of the mean scores reveals a different picture between participants with higher and lower proficiency levels. Participants with a lower proficiency level show an improvement for the items presented with context when compared with those without context (with context $M=0.311, S D=0.375$; without context $M=0.265, S D=0.315$ ). The opposite tendency was found for participants with a higher proficiency level, whose performance in idiom comprehension declined by just over 0.1 points when the items were presented without context (with context $M=0.164, S D=0.242$; without context $M=0.243, S D=0.299$ ). However, these differences between the categories were not found to be significant $(F(1,696)=2.367, p=0.124)$.

As far as the interaction between the context and the frequency is concerned, we found a marked difference between the mean scores for high-frequency and low-frequency items when they were presented with a context (see Figure 2). Participants scored an average of $M=0.837(S D=0.266)$ for the high-frequency items with context and only $M=0.017$ $(S D=0.034)$ for their low-frequency counterparts. In contrast, the difference between the mean scores for the highfrequency and low-frequency items considerably diminished when they were presented without context (high-frequency $M=0.301, S D=0.376$; low-frequency $M=0.212, S D=0.298)$. As expected, the results of the binary logistic regression revealed that the two-way interaction effect context $*$ frequency was significant $(F(1,696)=4.257, p=$ 
0.039), which means that presenting high-frequency idioms with context is associated with an increased likelihood for correct answers when compared with their low-frequency counterparts.

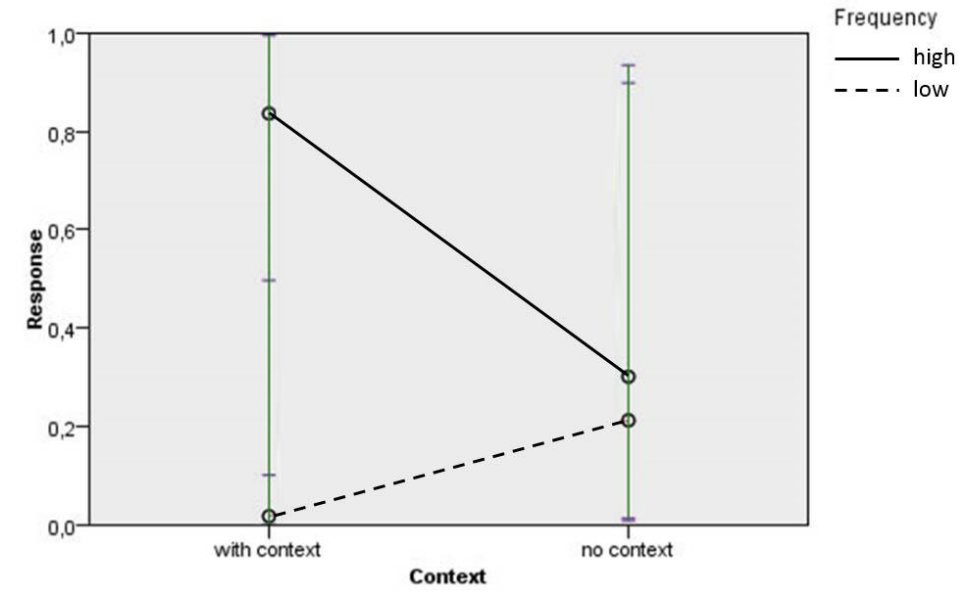

Figure 2. Results of the idiom comprehension test by L2 frequency and context (by-item analysis).

Finally, we looked at whether the use of context is modulated by the length of stay abroad. Analysis of the mean scores shows that an increasing length of stay is associated with poorer performance in the idiom comprehension test (see Table III). The binary logistic regression revealed a significant main fixed effect of the two-way interaction context * length of stay $(F(4,696)=3.604, p=0.006)$.

TABLE III.

RESULTS ON METAPHOR COMPREHENSION TEST (BY ITEM)
\begin{tabular}{|l|l|l|l|l|}
\hline Context & stay abroad & Mean & SD & N \\
\hline \multirow{3}{*}{ with context } & stay $<3$ months & 0.421 & 0.427 & 29 \\
\cline { 2 - 5 } & stay $\geq 3$ and $<6$ months & 0.175 & 0.252 & 22 \\
\cline { 2 - 5 } & stay $\geq 6$ months & 0.089 & 0.144 & 21 \\
\hline \multirow{3}{*}{ without context } & stay $<3$ months & 0.299 & 0.340 & 29 \\
\cline { 2 - 5 } & stay $\geq 3$ and $<6$ months & 0.280 & 0.327 & 22 \\
\cline { 2 - 5 } & stay $\geq 6$ months & 0.143 & 0.202 & 21 \\
\hline
\end{tabular}

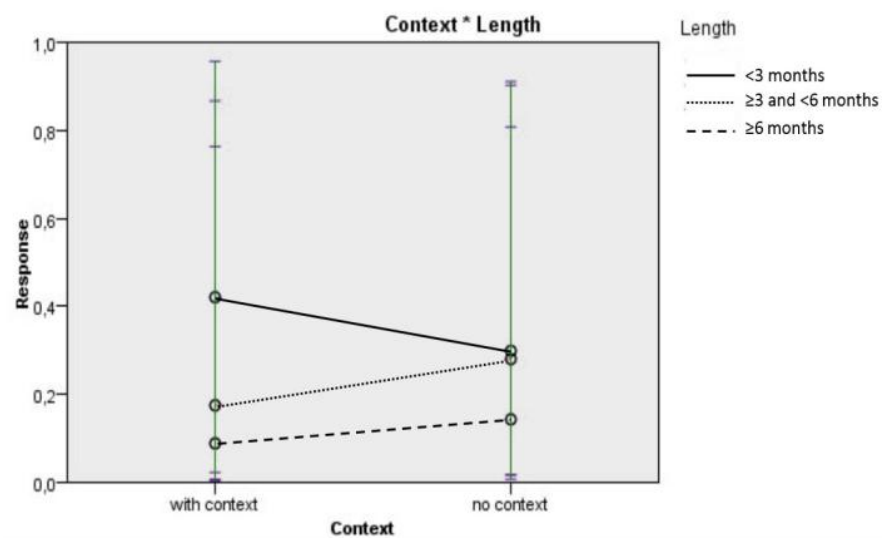

Figure 3. Results of the idiom comprehension test by length of stay abroad and context (by-item analysis).

Regarding the different categories of length of stay, the fixed coefficients showed significant negative effects for the participants with a short stay abroad ( $\geq 3$ and $<6$ months; $\beta=-1.225, z=-2.208, p=0.028)$ and with a longer stay $\operatorname{abroad}(\geq 6$ months; $\beta=-2.013, z=-3.120, p=0.002$ ) for the items with context when compared with the participants that had spent $<3$ months abroad. As for the items without context, only for participants with a longer stay abroad ( $\geq 6$ months) was a significant negative effect found $(\beta=-0.941, z=-2.248, p=0.025)$, whereas participants with a short stay abroad ( $\geq 3$ and $<6$ months) were not associated with a significantly worse performance in the test when compared with those with a stay of $<3$ months $(\beta=-0.079, z=-0.238, p=0.812)$.

\section{B. Qualitative Analysis of Learners' Answers}

The analysis in this section aims to provide deeper insight into how L2 learners coped with unknown L2 idioms and which sources of knowledge they used to infer the meaning. With regard to the use of contextual information, we observed that learners made several attempts to guess the meaning, which also led to false interpretations. For example, 
for the metaphorical expression auf den Kopf stellen [Engl. to turn something upside down] some participants suggested that it refers to planning something.

(2) "Häusliche Pflege, gerade wenn sie so lange währt, stellt das bisherige Leben vollkommen auf den Kopf. Man muss sich meist von allem verabschieden, was einem einst lieb und teuer war. Von Lebensentwürfen, von Träumen." (Prosinger, 2016, para. 7) [Engl. In-home nursing care that lasts for an extended period turns your life totally upside down. You must bow out of all those things that were so precious and beloved to you. Life plans, dreams.]

Response: Avoir en tête, à l'esprit [Engl. to have something in mind].

Furthermore, other responses seem to reflect the perceptions that a number of the participants had about the economic and political situation in Greece, to some extent biased by the overemphasis that press coverage in some countries has placed on the government's fraudulent economic practices. As (3) shows, some participants interpreted the metaphorical expression die Hände in den Schoß legen (Engl. to sit back and take it easy) as referring to corrupt and illegal activities of the Greek government, i.e. using funds from the EU earmarked for strengthening the economy. However, the expression is actually used to convey the idea that Greece is simply reluctant to put any effort into strengthening the economy.

(3) "Athen kann nicht erwarten, dauerhaft von den anderen EU-Staaten alimentiert zu werden, während es selbst mehr oder weniger die Hände in den Schoß legt." ("Griechen legen Hände in den Schoß und wir zahlen”, 2011, para. 4) [Engl. Athens cannot expect to be permanently maintained by the other EU states, while it sits back and takes it easy].

Response: Être impliqué dans des affaires obscures [Engl. to be involved in dirty deals], avoir du sang sur les mains [Engl. to have blood on one's hands $*$ to be guilty of something].

A closer examination of some individual answers reveals that the participants also strongly relied on their knowledge about general embodied experiences (e.g. motion, force, space, etc.) to infer the literal meaning from the idioms and then guess the figurative meaning, which is generally consistent with the assumptions made in Cieślicka's (2006) model. For example, many participants suggested that the metaphorical expression unter die Arme greifen (Engl. to grab someone under his arms ${ }^{*}=$ to help someone) refers to frightening someone (Fr. prendre quelqu'un par surprise). Indeed, the image evoked by the lexical meaning of the metaphorical expression fits well with a situation in which someone unexpectedly comes up from behind and grabs someone else under the arms to frighten him. However, the metaphorical expression in German conveys the physical situation where someone helps someone else by grabbing him under his arms and placing him upright, so that he can keep moving. Such plausible, but false interpretations were given by some participants who relied on the physical action evoked by the German metaphorical expression sich die Schulter klopfen (to tap yourself on the shoulder ${ }^{*}=$ to shower with compliments). Some of the answers included to encourage yourself (Fr. s'encourager) and to be close to one another (Fr. être très près l'un de l'autre). The first attempt accounts for the negative cross-cultural transfer from L1 to L2. In fact, the gesture of tapping on someone's shoulder is not used to congratulate someone, but to encourage him, which shows that the same concrete action is interpreted differently in both sociocultural contexts and can thus lead to misinterpretations. Consequently, we argue that to be successful, participants need to combine their knowledge about general embodied experiences with their knowledge about culturally embedded gestures. This supports fairly well the idea that culture-specific grounding directly affects the semantic transparency of idioms (Boers \& Demecheeler, 2001). In contrast, the second attempt shows that the lexical meaning of the individual constituents of the idiom can potentially evoke a different image, leading to a different overall interpretation. In fact, the action of tapping (klopfen) can be understood as the result of two individuals being very close to one another, which makes their shoulders (Schulter) come into contact. However, as the participants did not suggest any equivalent expressions for the item, no further conclusions can be drawn about the interpretation of the metaphorical meaning of the target expression.

Thus, the answers provide evidence of the general ability of learners to figure out the physical situation by using their general embodied experiences, select the relevant aspects and map them onto the target domain. However, as the selection of the relevant aspects from the source domain is often triggered by cultural beliefs, the mere activation of general embodied experiences (e.g. in the form of image schemes, cf. Oakley, 2007) does not automatically lead to the expected results. In other words, where cultural knowledge is needed to infer the meaning of the metaphorical expression, metaphor comprehension is seriously impaired. This finding is in solid agreement with the observations made by De Cock and Suñer (2018), who found that participants only attempted to guess the meaning of metaphorical expressions on the basis of their general embodied experiences, but did not provide any answer when metaphorical expressions used more specific knowledge about traditions or historical facts that were not accessible to them. The theoretical implications of this finding are discussed in the next section.

\section{DiSCUSSION}

This study addressed three research questions. The first was concerned with the facilitative effect of stay-abroad experience on the use of contextual information in L2 idiom comprehension. First, we looked into the general impact of stay-abroad experience on L2 idiom comprehension and found no marked differences between participants across the groups (with and without stay-abroad experience). This is consistent with the findings of Suñer (2018), but contrasts with those of the study by De Cock and Suñer (2018). This contradictory result might be explained by the fact that the topic domain tested in the latter study (linguistic taboo) was much more related to informal registers, which L2 learners 
are more likely to be exposed to during a stay abroad. Furthermore, analysis of performance in the idiom comprehension test revealed that a stay-abroad experience was not associated with more efficient use of contextual information to infer the meaning of idioms. These results do not appear to support the idea that L2 learners with a stayabroad experience might use the context more effectively to infer the meaning of L2 idioms because of their increased lexical abilities (De Keyser, 1991; Segalowitz et al., 2004; Wood, 2007) and well-developed communicative strategies (Freed, 1998; Lafford, 2004; Lafford, 2006; Montero et al., 2017). However, the results align well with the observation made in some previous studies suggesting a limited impact of stay-abroad experiences on vocabulary size (Collentine, 2004; Dewey, 2008; Ife et al., 2000; Segalowitz \& Dewey, 2004; Taguchi, 2011). Thus, we can conclude that the gains made by L2 learners during a stay abroad in terms of vocabulary size and communicative strategies do not seem to be directly relevant for developing a greater sensitivity to metaphorical idiomatic expressions in the L2. In addition, analysis of the participants' individual answers suggests that participants relied on both the context and their general embodied experiences, but that these factors were not enough to ensure successful interpretation. Rather, it seems that, to some extent, knowledge about the culturally embedded meaning of some physical actions and gestures could have contributed to a more accurate interpretation of conceptually different metaphorical expressions.

The second question asked to what extent learners with a stay-abroad experience are subject to L2 frequency effects in L2 idiom comprehension. It has been argued that only L2 learners with a stay-abroad experience would take advantage of high-frequency idioms in the same way as L1 speakers do (e.g. Aarnon \& Snider, 2010) because of their exposure to L2 authentic input and their greater sensitivity to idiomaticity (Ellis, 2012; Granger, 2001). Although highfrequency items were, in general, easier to comprehend than low-frequency items for all participants, a stay-abroad experience did not significantly increase this positive correlation, which is in disagreement with the predictions made by Kim and Kim (2012). Rather, the overall picture of the results supports the idea that participants at levels B2-C1 have already acquired a native-like sensitivity to idiomaticity in the sense that they already benefit from L2 frequency effects. However, in order to make such strong claims regarding the influence of L2 frequency on L2 idiom comprehension, a control group consisting of L1 speakers should have been included in the study. Such a baseline would have allowed us to investigate the extent to which the differences between high frequency and low frequency are comparable between L2 learner groups and L1 speaker groups.

As for the third research question on the relationship between proficiency level, length of stay and frequency regarding the use of contextual information in L2 idiom comprehension, the results are very heterogeneous. We found that presenting high-frequency idioms with context is associated with significantly better performance among all participants compared with their low-frequency counterparts. These findings seem to be in disagreement with the Literal Salience Model by Cieślicka (2006), which predicts a tendency for L2 learners to first access the most salient literal meaning of the idiomatic expression for the purpose of lexical inferencing, without making use of contextual clues (see also Giora, 1999, 2003). However, it can be argued that the presence of contextual information might have enhanced the quality of lexical inferencing for those idiomatic expressions whose meaning can be more easily accessed because of their high frequency. In contrast, the absence of a context considerably diminished the quality of lexical inferencing for low-frequency idiomatic expressions, since their literal meaning could not be easily inferred. In other words, the context only provides additional clues when the meaning of the idiomatic expression is already strongly activated due to its high frequency. Further research is therefore needed to look at learners' strategies during L2 idiom comprehension regarding the use of the context by using think-aloud protocols. Furthermore, length of stay has been found to have a negative impact on L2 idiom comprehension. One plausible reason for this striking result could be that, although it is important to be massively exposed to L2 authentic input during a stay abroad for the purpose of learning vocabulary, the distribution of the input over time seems to be much more crucial (Dewey, 2008). This means that massive exposure to L2 texts containing idiomatic expressions in the at-home learning context could be more beneficial in terms of L2 idiom comprehension than having the same exposure over a longer period of time during a stay abroad.

Although this study substantially contributes to a deeper understanding of the factors modulating the impact of stayabroad experiences on L2 idiom comprehension, it does have some methodological limitations. Whereas the sample size was relatively large in terms of numbers of participants, more idiomatic expressions for each category should have been included in order to balance against within-cluster similarity. Furthermore, participants' language proficiency was determined on the basis of self-assessment judgements as well as the language learning progression in the respective degree programs. Therefore, in order to increase the accuracy of the observations regarding the influence of language proficiency on L2 idiom comprehension, more reliable testing instruments (e.g. standardized placement tests) should be used. Finally, it is worth noting that not all participants were enrolled in the same degree program, so that they were not fully comparable regarding their academic background. In fact, participants enrolled in the translation and interpreting program could have taken advantage of their well-developed translation skills, in contrast to those participants studying modern languages from a linguistic and literary point of view.

\section{CONCLUSIONS}

The aim of this study was to examine whether a stay-abroad experience is associated with increased conceptual fluency with regard to L2 idiom comprehension. Taken together, the results suggest that the benefits of a stay-abroad experience do not translate into better performance in L2 idiom comprehension. More specifically, the analysis found 
no evidence of either better use of contextual information by L2 learners with stay-abroad experience or a facilitative effect of frequency effects. Rather, it seems that the use of context is much more affected by frequency effects than by the stay-abroad experience, which indicates that the L2 input offered in more formal learning contexts might also play an important role in L2 idiom comprehension. Thus, in order to increase their proficiency in areas such as L2 conceptual fluency, L2 learners in the stay-abroad learning context would also need to have enhanced L2 input that offers multiple occurrences and prompts them to notice target idiomatic expressions.

\section{REFERENCES}

[1] Arnon, I. \& N. Snider. (2010). More than words: Frequency effects for multi-word phrases. Journal of Memory and Language $62,67-82$.

[2] Azuma, M. (2009). Positive and negative effects of mother-tongue knowledge on the interpretation of figurative expressions. Papers in Linguistic Science 15, 165-192.

[3] Boers, F. (2003). Applied linguistics perspectives on cross-cultural variation in conceptual metaphor. Metaphor and Symbol 18, 231-238.

[4] Cameron, L. \& G. Low. (1999). Metaphor. Language Teaching, the International Journal for Language Teachers, Educators and Researchers 32. 77-96.

[5] Charteris-Black, J. (2002). Second language figurative proficiency: A comparative study of Malay and English. Applied Linguistics 23.1, 104-133.

[6] Chuang, Y.-Y. (2013). A Study of the Relationship between College EFL Learners'. Vocabulary Size and Idiomatic Reading Comprehension. NCUE Journal of Humanities 7, 59-76.

[7] Cieślicka, A. (2006). Literal salience in on-line processing of idiomatic expressions by second language learners. Second Language Research 22.2, 115-144.

[8] Collentine, J. (2004). The effects of learning contexts on morphosyntactic and lexical development. Studies in Second Language Acquisition 26.2, 227-248.

[9] Cooper, T. (1999). Processing idioms by L2 Learners of English. TESOL Quarterly 33.2, 233-62.

[10] Danesi, M. (2008). Conceptual errors in second-language learning. In S. De Knop \& T. De Rycker (eds.), Cognitive Approaches to Pedagogical Grammar. Berlin \& New York: Mouton de Gruyter, 231-256.

[11] De Cock, B. \& F. Suñer. (2018). The influence of conceptual differences on processing taboo metaphors in the foreign language. In A. Pizarro (ed.), Linguistic Taboo Revisited. Novel Insights from Cognitive Perspectives. Cognitive Linguistics Research Series (CLR). Amsterdam: Mouton de Gruyter, 379-395.

[12] De Keyser, R. (1991). Foreign language development during a semester abroad. In B. F. Freed (ed.), Foreign language acquisition research and the classroom. Lexington, MA: D. C. Heath, 104-119.

[13] Dewey, D. (2008). Japanese vocabulary acquisition by learners in three contexts. Frontiers: The Interdisciplinary Journal of Study Abroad 15, 127-148.

[14] Ellis, N. C. (2012). Formulaic Language and Second Language Acquisition: Zipf and the Phrasal Teddy Bear. Annual Review of Applied Linguistics 32, 17-44.

[15] Ferreira, L. C. (2008). A psycholinguistic study on metaphor comprehension in a foreign language. ReVEL 6.11, 1-23.

[16] Freed, B. F. (1998). An overview of issues and research in language learning in a study abroad setting. Frontiers IV, 31-60.

[17] Freed, B., N. Segalowitz \& D. Dewey. (2004). Context of learning and second language fluency in French: Comparing regular classroom, study abroad, and intensive domestic immersion programs. Studies in Second Language Acquisition, 26.2, $275-301$.

[18] Gibbs, R. W. Jr. (2007). Idioms and formulaic language. In D. Geeraerts \& H. Cuyckens (eds.), The Oxford handbook of cognitive linguistics. Oxford: Oxford University Press, 697-725.

[19] Giora, R. (1999). On the priority of salient meanings: studies of literal and figurative language. Pragmatics 31.7, 919-929.

[20] Giora, R. (2003). On our mind: Salience, context, and figurative language. New York: Oxford University Press.

[21] Granger, S. (2001). Prefabricated patterns in advanced EFL writing: Collocations and formulae. In A. P. Cowie (ed.), Phraseology: Theory, analysis, and applications. Oxford, UK: Oxford University Press, 145-160.

[22] Griechen legen Hände in den Schoß und wir zahlen. (2011, December 30). Die Welt. Retrieved from https://www.welt.de/politik/.

[23] Ife, A., G. Vives Boix and P. Meara. (2000). The impact of study abroad on the vocabulary development of different proficiency groups. Spanish Applied Linguistics 4, 55-84.

[24] Irujo, S. (1986). Don't put your leg in your mouth: Transfer in the acquisition of idioms in a second language. TESOL Quarterly 20, 287-304.

[25] Karlsson, M. (2013). Quantitative and Qualitative Aspects of L1 (Swedish) and L2 (English) Idiom Comprehension. Studies in Second Language Learning and Teaching 3.2, 293-319.

[26] Kim, S. H. \& J. H. Kim. (2012). Frequency Effects in L2 Multiword Unit Processing: Evidence from Self-Paced Reading. TESOL Quarterly 46.4, 831-841.

[27] Kinginger, C. (2009). Language learning and study abroad. A critical reading of research. New York: Palgrave Macmillan.

[28] Klemm, T. (2014, October 17). Jedermann ein Usain Bolt. Frankfurter Allgemeine Zeitung. Retrieved from http://www.faz.net/aktuell/sport.

[29] Lafford, B. (2004). The effect of the context of learning (classroom vs. study abroad) on the use of communication strategies by learners of Spanish as a second language. Studies in Second Language Acquisition 26.2, 201-226.

[30] Lafford, B. (2006). The effects of study abroad vs. classroom contexts on Spanish SLA: Old assumptions, new insights and future research directions. In C. A. Klee \& T. L. Face (eds.), Selected proceedings of the 7th conference on the acquisition of Spanish and Portuguese as first and second languages. Somerville, MA: Cascadilla Proceeding Project, 1-25.

[31] Llanes, À. \& C. Muñoz. (2013). Age effects in a study abroad context: Children and adults studying abroad and at home. Language Learning 63.1, 63-90. 
[32] Liontas, J. I. (2002). Context and idiom understanding in second languages. EUROSLA Yearbook 2, 155-185.

[33] Littlemore, J. (2008). The relationship between associative thinking, analogical reasoning, image formation and metaphoric extension strategies. In M. S. Zanotto, L. Cameron, \& M. C. Cavalcanti (eds.), Confronting metaphor in use: An applied linguistic approach. Amsterdam, Philadelphia: John Benjamins, 199-222.

[34] Lord, G. (2010). The Combined Effects of Immersion and Instruction on Second Language Pronunciation. Foreign Language Annals 43.3, 488-503.

[35] Mora, J.C. \& M. Valls-Ferrer. (2012). Oral fluency, accuracy and complexity in formal instruction and study abroad contexts. TESOL Quarterly 46.4, 610-641.

[36] Littlemore, J. \& G. Low. (2006). Metaphoric competence and communicative language ability. Applied Linguistics 27.2, 268294.

[37] Littlemore, J., T. Krenmayr, J. Turner \& S. Turner. (2014). An investigation into metaphor use at different levels of second language writing. Applied Linguistics 32.4, 208-429.

[38] Liu, D. (2008). Idioms: Description, comprehension, acquisition, and pedagogy. New York, NY: Routledge.

[39] Montero, L., R. Serrano \& A. Llanes. (2017). The influence of learning context and age on the use of L2 communication strategies. The Language Learning Journal 45.1, 117-132.

[40] Oakley, T. (2007). Image schemas. In D. Geeraerts \& H. Cuyckens (eds.), The Oxford Handbook of Cognitive Linguistics. Oxford/New York: Oxford University Press, 214-235.

[41] Pinar, A. (2016). Second Language Acquisition in a study abroad context: Findings and research directions. Colombian Applied Linguistics Journal 18.2, 83-94.

[42] Prosinger, W. (2016, January 25). Wenn das Leben auf den Kopf gestellt wird. Der Tagesspiegel. Retrieved from https://www.tagesspiegel.de.

[43] Rohani, G., S. Ketabi \& M. Tavakoli. (2012). The effect of context on the EFL learners' idiom processing strategies. English Language Teaching 5.9, 104-114.

[44] Saleh, N. \& N. Zakaria. (2013). Investigating the difficulties faced in understanding, and strategies used in processing English idiom by the Libyan students. International Journal of English Language and Translation Studies 1.2, 69-90.

[45] Segalowitz, N., B. Freed, J. Collentine, B. Lafford, N. Lazar \& M. Díaz-Campos. (2004). A comparison of Spanish second language acquisition in two different learning contexts: Study abroad and the domestic classroom. Frontiers: The Interdisciplinary Journal of Study Abroad 10, 1-18.

[46] Sunderman, G. \& J. F. Kroll. (2009). When study abroad experience fails to deliver: The internal resources threshold effect. Applied Psycholinguistics 30.1, 79-99.

[47] Suñer, F. (2018). The interplay of cross-linguistic differences and context in 12 idiom comprehension. Research in Language 16.4, 495-513.

[48] Taguchi, N. (2011). The Effect of L2 Proficiency and Study-Abroad Experience on Pragmatic Comprehension. Language Learning 61.3, 904-939.

[49] Taki, S. \& M. R. Namy. (2013). The Role of L1 in L2 Idiom Comprehension. Journal of Language Teaching and Research 4.4, 824-833.

[50] Trenchs-Parera, M. (2009). Effects of formal instruction and a stay abroad on the acquisition of native-like oral fluency. The Canadian Modern Language Review 65.3, 365-393.

[51] Türker, E. (2016). The role of L1 conceptual and linguistic knowledge and frequency in the acquisition of L2 metaphorical expressions. Second Language Research 32.1, 25-48.

[52] Wood, D. (2007). Mastering the English formula: Fluency development of Japanese learners in a study abroad context. JALT Journal 29.2, 209-23.

[53] Wray, A. (2002). Formulaic language and the lexicon. Cambridge, England: Cambridge University Press.

Ferran Suñer majored in German Studies at the Universities of Barcelona (Spain) and Cologne (Germany) in 2005. He completed his Ph.D. in German as a Foreign Language and Psycholinguistics at the LMU Munich (2011) and is currently professor in German Didactics and Linguistics at the Catholic University of Louvain (UCL) (Belgium). He taught at the Institute for German as a Foreign Language at LMU Munich and supervised several post degree distance learning course for teachers of German (2011-2015). He was a visiting professor at the University of California Davis (USA), the German Jordanian University (Jordan), and the University Omar Bongo (Gabon, West Africa). Also, he authored several teaching materials for a continuing education program which is distributed internationally by the Goethe-Institute. His research focuses on cognitive aspects of language teaching and learning, the acquisition of L2 conceptual competence, and the use of new media in the FL classroom. 